\title{
An Ecological Model for Counselor Pedagogy Incorporating Service Learning
}

Margery J. Shupe, (E-mail: Shupe@xavier.edu), Xavier University

William P. O’Connell, (E-mail: Oconnell@xavier.edu), Xavier University

\begin{abstract}
This pilot study examined how one Graduate Counseling Program initiated improvements in counselor training pedagogy through incorporating a service-learning project with computer technology into an entry-level course for graduate students. The service learning experience was designed to advance university and community collaboration and teach students about social justice and advocacy in the field of mental health. Students were placed in several agencies that represented grossly underserved populations. A holistic approach incorporating both qualitative and quantitative procedures was utilized for the analysis of this study. The authors developed a non-standardized questionnaire containing specific questions pooled from the CACREP guidelines for counselor training.
\end{abstract}

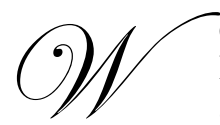
e live and work in a society that is undergoing unprecedented changes (Lewis, Lewis, Daniels, \& D'Andrea, 2003) that are also reflected in the counseling profession. These changes are the result of an emerging paradigm shift (Lewis, et al, 2003) from the traditional model of training counselors that focused upon treating the individual towards a new ecologically based model that emphasizes cultural sensitivity and community building initiatives (Osborne, Collison, House, Gray, Firth, \& Lou, 1998). This new trend encourages counselors to search for innovative ways to address the mental health needs of $21^{\text {st }}$ century clientele. Lewis, et al, (2003) suggest that counselors look to this new paradigm to foster the mental health needs of clients as well as to promote more tolerant, responsive, and caring communities across the United States. In order to do so, mental health practitioners must acquire the types of multicultural competencies that are necessary to work effectively, ethically, and respectfully with persons who come from diverse groups and backgrounds (Arredondo, Toporek, Jones, Locke, Sanchez \& Stadler, 1996; Faulkner, 2001). This is no easy task - convincing counseling students that they are in fact agents of social change. Therefore, the authors developed a new learning model based upon recent trends and professional literature in community counseling that incorporates service learning as a way to provide students with the rich, intimate, direct and personal examination of the complexities involved in community counseling. Service learning helps prepare counseling students with knowledge and important life skills intrinsic to life as a community counselor.

\section{PURPOSE OF STUDY}

The theoretical basis for incorporating service learning into the course redesign was based upon an ecological model (Bronfenbrenner, 1979, Lewis et al, 2003). Ecological models are particularly important in counseling because they assume that the counselor-client relationship cannot be understood apart from the multiple systems in which both live (Conyne, 1985; Munger, 1997; Van Voorhis, Braswell, \& Morrow, 1997). Just as the counselor experiences these systems of influence, a client also experiences an ecological system. Thus, a service learning experience allows for students (future counselors) to deeply and intimately examine the ecological systems at work in the community from a pioneering, experiential perspective that cannot be replicated in a classroom lecture. The purpose of this exploratory study was to learn if the service learning experience assisted students with expanding their understanding of their future profession. Additionally the purpose of the study was to evaluate if the students developed a deeper level of understanding of the issues of social justice and advocacy in our complex world today. 


\section{REVIEW OF THE LITERATURE}

\section{Service Learning}

Service learning takes students out of their regular zone of contact and brings their education to life (Anderson, 1995; Gose, 1997). According to Spohn (2001), a passion for justice does not come from reading books or listening to lectures, it comes from personal experience. Service learning advocates for educational programs to take students out of the classroom and into the soup kitchen, nursing home, into the inner city, or to the reservation where they learn to care about people who are suffering injustice. Service learning then is ultimately a very effective and innovative pedagogy for empowering students to become more knowledgeable and more actively involved in their own communities. Furthermore, it provides them with the opportunity to perceive themselves as agents of social change (Agha-Jaffar, 1997).

Service learning provides a direct way in which counseling faculty can formally integrate community service with academic study. Service learning allows for students to observe in a direct manner, anything that is related to the counseling profession such as tasks, client populations, professional roles, and agency function. It is different from engaging in professional activities, as they are not in a position to provide direct client services. The service experience allows for students to observe mental health board meetings, Continuous Quality Improvement (CQI) meetings, case review meetings, and agency board meetings. These indirect observational experiences can also be very profitable from a pedagogical experience because they allow for the students to develop a greater understanding of the actual internal functioning of the agency as well as how the agency functions within the community at large. Students today seem much more visually and experientially oriented than students of the past (Federico, 2001; Kearsley, 1998). If we as faculty can encourage students to learn more about the world and their place in it, our students are likely to become better counselors. Developing a global perspective encourages students to view their clients from a multidimensional and comprehensive perspective which is important in truly experiencing their world as they (the clients) experience it. Incorporating service learning into a counselor-training program actively allows for the students to bridge the theory-practice gap in preparation for practicum, internship and professional practice. Through proficient engagement and the development of passion, faculty can use service learning to develop fruitful inquiry in the mind of the student (Kershaw, 1998; Spohn, 2001).

Service learning allows for great latitude in terms of creativity on the part of the faculty and the service learning site supervisor. By using creative approaches, service learning can be designed to be highly relevant to the beginning-counseling students learning needs, future career goals, and desire to work with clients in a particular specialty area (i.e. substance abuse, career, geriatric, children, grief). Service learning is not designed to substitute or replace counseling practicums or internships since the goal of the service learning is not necessarily focused on improving the student's helping skills, as in the case of practicum or internship experiences. Rather, service learning is about broadening student's perspective of counseling needs in the local community, increasing understanding of how agencies function, and teaching them the multiple systems in which their clients will exist within the community at large.

When carefully conceived and scrupulously implemented, service learning contributes to the highest quality education and can be a gold mine from a pedagogical perspective (Brand, 2001; Gose, 1997; Hook \& Fern, 1983; Miller \& Neese, 1997; Swezey, 1990; Ward \& Wolf-Wendel, 2000). The characteristics of service learning are many. Community service learning operates as the vehicle for the achievement of specific academic goals and objectives. It provides structured time for students to reflect on their service and learning experiences through a mix of writing, reading, speaking, listening, and creating in small and large groups and individual work (Miller \& Neese, 1997). The result can be an enhanced capacity on the part of the students to develop their insights and personal qualities to the fullest extent (Cooper, 2001; Garcia, 2000).

\section{Counselor Professional Identity \& Career Development}

Many counseling students today are culturally encapsulated. Service learning provides students a chance to learn about themselves in many ways, among them: development of the cardinal counselor skill of empathy, learning 
about self in new situations and as a professional, exposure to diverse populations and settings, and learning about what client populations might be a good fit for them as a future counselor. Enhanced professional self-knowledge and identity development allows for the students to return from this experience with a clarified vision of themselves for the future. Many studies (Billig, 2000; Hengel \& Shumer, 1997) indicate that students acquire specific knowledge about careers directly from the service they perform. Career related outcomes tend to be optimized if there is an intentional connection to workplace skills or career pathways (Super, 1990). Another main purpose of service learning is to assist counseling students in recognizing their altruistic qualities and promote a sense of caring for others (Bandura, 1977; Bandura, 1986; Kiselica \& Robinson, 2001; Miller \& Neese, 1997). Thoughtfully organized service experiences can enhance a realistic sense of self-esteem through working to help others (Seymour \& Vaccaro, 2001).

\section{COURSE RE-DESIGN}

\section{Before}

The professional identity course re-designed in this study was a two-credit hour semester course required for all graduate-counseling students and was also required to meet State licensure requirements. It was a survey course of the historical developments and current trends influencing the helping professions and is a course most likely found in every counseling program in the United States as it addressed CACREP guidelines and standards for teaching about Counselor Professional Identity (i.e. professional identity, agency settings, agency systems/functions) and Social and Cultural Foundations (i.e. multicultural awareness, diversity training) (CACREP, 2001). The original course objectives were to teach beginning (novice) counseling students about the history and development of the field of counseling as well as introduce them to the various agency, community, and client populations that they may work with in the future. The "old", and perhaps, outdated approach of the course was structured to include lecture, readings, and papers which did not allow for sufficient personal exploration so that counseling students could begin to learn about their strengths, weaknesses, and their personal style as a future clinician. Additionally, the old course format did not allow for students to examine issues of social justice, advocacy, as well as the multiple systems of influence in clients' lives.

\section{After}

The "new" approach to the professional identity course incorporated dimensions of advocacy, direct service (through service learning) and interactive technology. The new course design aimed to enhance students' understanding of various community settings, but also served to encourage students to begin to examine which setting might be a good fit for them personally and professionally as a future clinician. Additional objectives of the course were the following: understanding of important themes and historical development of the counseling profession as well as various functions of professional counselors in community based settings; professional identity development as a counselor; understanding of professional advocacy and social justice in the field of mental health; an enhanced understanding of professional roles, functions, and relationships with other human service providers; and exposure to various client populations in the community (CACREP 2001). These objectives were met through the following assignments: classroom discussions/reflection sessions, on-line journaling, advocacy letter, counselor interview, and professional integrated learning essay.

Students were required to perform weekly service learning (approximately 2 hours per week) during the middle six weeks of the semester. This timing allowed for the professors to assist the students with preparing to begin the service learning experience through the regularly scheduled class meetings on campus.

Due to the proliferation of technology in the counseling and related human service fields this course utilized interactive Blackboard technology. Blackboard is an institutional course management system which allows for all users to easily access course reserve materials, institutional resources, email, discussion boards, perform literature review, access important links to counseling websites, and personal tools for organization. Specifically, Blackboard was helpful from a pedagogical technique as it teaches students about how to use computers efficiently and effectively as a way to communicate with their professors, with other students enrolled in the course, and served as a means to 
post journals and give and receive feedback about their service learning experiences. Through using Blackboard students were able to engage in depthy discussions about their experiences, feelings, and issues they were learning about within their service learning sites.

Technology quite simply, is a necessary skill for counselors living and working within the $21^{\text {st }}$ century (Lewis, Courso, Khan \& Wilson, 2000; Stafford-Levy \& Wiburg, 2000). Additionally, counselor education programs have been directed by CACREP (2001) and other ACA guidelines to work to incorporate technology to prepare and produce technologically proficient counselors who are capable of advancing the profession (Lewis, Coursol, Khan, \& Wilson, 2000).

\section{METHODOLOGY}

The purpose of this study was to assess the success of a service-learning project conducted during an entrylevel counselor education course for graduate students. A holistic approach incorporating both quantitative and qualitative procedures was utilized in order to gather the data in the most comprehensive form.

\section{Participants}

The participant sample consisted of eleven students who were enrolled in professional identity course in the spring semester, at a small private, Midwestern university.

\section{Initial Procedure}

The participants gave informed consent to participate in the study. Students were assured that their responses would be kept anonymous and confidential. Additionally, they were informed that participation was voluntary and would in no way affect their grade. A brief demographic questionnaire including items inquiring about level of training and amount of previous clinical experience was administered to the participants.

\section{Quantitative Procedures}

The authors developed a non-standardized questionnaire containing thirty specific questions designed to assess students' knowledge and competency in history and systems of community and agency counseling (see Appendix 1). The questions were developed from the CACREP (2001) guidelines for counselors in training and professional literature regarding community counselor competencies and from research by Melcher, Hays, Wiljanen, \& Kolocek, (1996). The quantitative procedure utilized a single case pre-test and post-test design whereby students were asked to respond to questionnaire items before the start of the course and again after completion of the course. Students rated their competency on a scale of 1 to 7 , where 1 was the most competent or strongly agree with the statement and a choice of 7 would mean that the student felt the least competent or strongly disagreed with the statement.

\section{Qualitative Procedures}

The authors developed an open ended questionnaire in which students were asked to elaborate on their service learning experience in terms of their role as a counselor, the agency setting, the community in which the agency operated, the social justice aspect of the experience, the course in general and how the experience has impacted the students' attitudes and knowledge regarding the role they filled during the experience. This questionnaire was administered at the conclusion of the semester. All data retrieved from the questionnaires were stored, categorized and coded. Individual questionnaires were built into analytic files using EXCEL, and were sorted using a simple coding scheme. The purpose of this analysis was to assess attitude and the amount of relevant interaction, not just content. 


\section{RESULTS}

\section{Demographics}

A total of 11 graduate students completed the survey. Graduate students ranged in age from 22 to 44 years with an average age of 31 . Nine out of the 11 students were female, seven were white females and two were African American females. The two male students were both white. In terms of education, all students had completed a Bachelor's degree. Only one out of the eleven students had a graduate degree. The majority of the students (8) were enrolled in their masters program on a part-time status. All but one of the students had employment experience in human services. A little more than half of the students had some prior employment experience in community counseling settings. Only two of the eleven students reported completing a service-learning project in the past. Four of the eleven students reported no prior employment experience in community counseling. One student did not answer the questionnaire.

\section{Quantitative Results}

When reviewing student responses to the same thirty questions at the completion of the service-learning course, it was evident that students' knowledge and competence in history and systems of community and agency counseling was enhanced. All means were below three and the standard deviations for all questions had been reduced. The students felt the least competent in the following areas at the beginning of the course:

1. Best practice principles for common diagnostic presentations in agency settings (Question 3)

2. The relationship between major historical developments and counselor identity (Question 10)

3. The benefits and limitations of research to program development and evaluation (Question 11)

4. Knowledge of professional organizations, such as ACA, its divisions, branches, and affiliates, including membership benefits, activities, services to members, and current mission and philosophy. (Question 14)

There was a statistically significant increase in perceived competence in all the above areas after the course was completed.

\section{Qualitative Results}

Due to the extensive data available using qualitative measures, the results are reported using a case study comparison between a non-experienced student and an experienced student. The case studies are compared and contrasted.

\section{Non-experienced Student}

Katie is a 32-year-old Caucasian female with an undergraduate degree in communications. She reported no experience in human services or counseling prior to this course. Katie's service learning project included work at an agency that provided education and counseling to adolescent females suffering from various eating disorders. She described the at-risk population as socially stigmatized with highly distorted images of the female body, beauty and health. In exchange for observing treatment groups with the clients at the agency, Katie performed tasks such as contacting insurance companies, updating the program website and assisting the office manager in organizing a marketing mailer. Upon completing her first experience in a counseling center, Katie believed she had a tremendous desire to help others in need, however, she recognized the complexity of counselor responsibility in managing client concerns, documentation, requirements of funding sources and promoting the agency services in the community. For Katie, the service learning was particularly enhanced by the use of an on-line discussion board that allowed her to share some of her feelings with classmates about starting out in the agency and identifying similar experiences. Katie reported she was less interested in learning about the administrative functions of the agency and more interested in learning group facilitation skills. She plans to find an internship experience that will include group work. Katie noted she was very uncertain about her decision to enter the counseling field and found herself more committed to continuing her counseling studies at the end of the service learning project. 


\section{Experienced Student}

Danielle is a 32-year-old African American female with a graduate degree in school psychology. She has worked in the field of human services for over seven years in a school setting. She reports no experience in community counseling. Danielle's service learning experience occurred at an agency serving clients diagnosed with HIV/AIDS. In exchange for observing support groups for clients, Danielle assisted the program supervisor in organizing files and charts for an upcoming audit. She perceived the at risk population to be highly stigmatized by the community and susceptible to unfair discriminatory practices by client families, employers, healthcare and government agencies. The service learning experience reminded Danielle of the tremendous responsibility one assumes in helping others at a professional level. In addition, she noted the reward of participating in the positive changes that people can make in their lives while providing professional support. Danielle found her experiences valuable; however, she had a desire to learn more about funding needs of the agency and means of obtaining grants to support the mission of the agency.

\section{Comparison of Non-experienced and Experienced Students}

The description of two students' perceptions of service learning indicates that service learning provides an opportunity to evaluate one's role as a future counselor in a community setting. Observing at risk clients helps student's see first hand persons in need and the types of interventions available to the clients. The non-experienced student found the experience invaluable in reaffirming her decision to enter the field of community counseling. The experienced student recognized her desire to learn about other responsibilities of the community counselor such as sustaining the mission of the agency in the community. The non-experienced counselor was more interested in the development of the client-counselor relationship. The experienced student was more interested in learning about funding sources, agency organization and the development of a best practice model. Additionally, both students chose to work with populations unfamiliar to them. The group of young females with eating disorders and clients living with HIV/ AIDS experienced social stigmas. This information was gathered through conversations with staff and observation of therapy and support groups.

\section{DISCUSSION}

Based on quantitative findings, the course did enhance knowledge and competency in the area of history and systems of community and agency counseling. In particular, the four questions in which students showed the least competency at the beginning of the course, showed statistically significant increase in competency $(\mathrm{p}<.05)$ after the course. However, stating that the course increased competency is not enough. A number of related questions must be addressed including: How did the course increase competency? In what ways did the role of the student in the service learning setting increase their learning and experience? How did the course increase awareness of social justice issues in community counseling? These are larger questions that address the true magnitude of impact on a student's experiential learning. With this in mind, the rich data from the qualitative study helped to illuminate the findings.

Service learning is an opportunity to observe and reflect on the multiple systems of influence in the counselor client relationship. This study indicates that service learning should be structured in terms of identifying overall goals, means of communicating learning and the discussion of issues in social justice. The study also indicates that students at different levels of experience in the human service learning field will most likely differ in their learning goals. Therefore, the counselor educator ought to carefully match service learning sites with the developmental level of the student.

\section{Limitations}

While this study makes an important contribution to the literature, it has its limitations. These include the use of a small sample size for this pilot study, and a lack of diversity among the participants, which limits the generalizability of the results. Accordingly, the study should be considered exploratory and future studies should include larger and more diverse groups of participants. 
When considering the implementation of a project such as this, it is wise to take into account that professors are already burdened by heavy teaching loads and may not have the time to arrange service learning sites (Gose, 1997). There may also be concern with flooding community groups with more volunteers than they can use. Additionally, it is plausible that such faculty research and development initiatives in service learning will not receive the credit or recognition it is due in the tenure process (Spohn, 2001). University administrators and reappointment and tenure committees may need to consider what sort of faculty development programs could encourage socially engaged scholarship (Spohn, 2001).

\section{Implications/Recommendations}

There are many worthwhile implications that resulted from this study. In particular students will form connections within the community which will be mutually beneficial for all parties. Students involved in the course contributed in a positive way to the community agencies, which were in many cases, under funded and understaffed. The relationship was reciprocally beneficial, for the student, for the community, and undoubtedly the university. Administrators can also view this as an inexpensive method to educate students (Gose, 1997), as this experience was undoubtedly pedagogically rich.

Introducing counselor education students to the application of technology is important, as they may not recognize its potential because of limited knowledge, training and experience (Lewis, et al, 2000). Programs need to adopt proactive measures that enable students to develop basic technological skills and also learn how to use technology to facilitate the counseling process. This course's technology component was purposefully designed to be interactive through the use of on-line journaling and fostered a good deal of connection amongst the students as they discussed issues in social justice as related to their service learning sites. These activities provided tangible experiences and hopefully will lead to the development of transferable technology skills that students will need in their professional career.

\section{CONCLUSION}

This novel strategy of incorporating service learning into counselor preparation courses brought forth a deeper level of understanding in several ways. Service learning enhanced the beginning counselor's development of professional identity, increased their understanding of how agencies function, and made for a much meaningful examination of self and settings.

For counselors in training the service experience crystallized an understanding of their role as an agent of social change and brought them to a deeper level of understanding of the issues involving mental health and social justice. In particular, the students came away with increased competence with issues in ecological counseling, and diversity, and the experience served to clarify their role as future counselors. An additional benefit of using service learning in counselor training pedagogy is that it begins to prepare them for their forthcoming practicum and internships, even perhaps relieving a bit of anxiety.

Service learning provides a rich resource for community based learning in so many ways. Through using service learning in counseling programs we can immerse the student in diverse settings that will better prepare them to be counselors of the future. Thus initiating a service project not only helps the students to enhance their selfknowledge but also is mutually beneficial at making a difference in the community with educational and personal benefits accruing as a natural consequence of working together.

Acknowledgments: The authors would like to thank the Faculty Development Committee at Xavier University for the Wheeler Award, as well as the Dean's Grant from the College of Social Sciences, both of which granted the funds which were used to support this project. 


\section{REFERENCES}

1. Agha-Jaffar, T. (2000). From theory to praxis in women's studies: Guest speakers and service learning pedagogy. Feminist Teacher, 13 (1), 1-11.

2. Anderson, J. D. (1995). Students' reflections on community service learning. Equity and Excellence in Education, 28(December), 38-41.

3. Arredondo, P., Toporek, R., Brown, S.P., Jones, J., Locke, D.C., Sanchez, J., \& Stadler, H. (1996). Operationalization of the multicultural counseling competencies. Journal of Multicultural Counseling \& Development, 24, 42-78.

4. Bandura, A. (1977). Self-efficacy: Toward a unifying theory of behavior change. Psychological Review, 84, 191-215.

5. Bandura, A. (1986). The explanatory and predictive score of self-efficacy theory. Journal of Social and Clinical Psychology, 4, 359-373.

6. Billig, S. H. (2000). The effects of service learning. The School Administrator, 14-18.

7. Brand, J. S. (2001). Jesuit law schools and the pursuit of justice: Unique opportunities, unique responsibilities. Conversations, 19 (Spring), 28-35.

8. Bronfenbrenner, U. (1979). The ecology of human development. Cambridge, MA: Harvard University Press.

9. CACREP Accreditation Manual, ( $\left(1^{\text {st }}\right.$ Ed.) (2001). Alexandria, VA: American Counseling Association.

10. Conyne, R. (1985). The counseling ecologist: Helping people and environments. Counseling and Human Development, 18 (2).

11. Cooper, M. (2001). Reflection: Getting learning out of serving. Web citation (http://www.fiu.edu/ $\sim$ time4chg/Library/fourthings.html).

12. Faulkner, V. (2001). Making Multicultural Education "Real". Teaching in higher education, 6 (4), 473-485.

13. Federico, P.A. (2001). Academic departments and student attitudes toward different dimensions of webbased education. Journal of Educational Computing Research, 25 (2), 159-175.

14. Garcia, R. M. (2000). Service learning and community collaboration. Community college journal, 70 (3), 3335.

15. Gose, B. (1997). Many colleges move to link courses with volunteerism. The Chronicle of Higher Education, 44 (Nov. 14 '97), A45-A46.

16. Hengel, M. S. \& Shumer, R. D. (1997). Service learning and Evaluation: A Brief Review of Resources and Readings. A "Link" Piece: Connecting Theory with Practice. Minnesota Univ., St. Paul. National ServiceLearning Cooperative Clearinghouse, 2-14.

17. Hook, W. F. \& Fern, P. S. (1983). Internships in social science: An historical perspective and suggestions for the future. Innovative Higher Education, 8 (Fall/ Winter), 38-44.

18. Kearsley, G. (1998). Engagement theory: A framework for technology-based teaching and learning. Educational Technology, 38 (5), 20-23.

19. Kershaw, A. (1998). From order to chaos: The impact of educational telecommunications on post-secondary education. Higher Education, 35 (Apr. '98), 285-298.

20. Kiselica, M. S. \& Robinson, M. (2001). Bringing advocacy counseling to life: The history, issues, and human dramas of social justice work in counseling. Journal of Counseling and Development, 79 (4), 397.

21. Lewis, J., Coursol, D., Khan, L., \& Wilson, A. (2000). Life in a dot.com world: Preparing counselors to work with technology. The University of New England, Australia, 2-16.

22. Lewis, J.A., Lewis, M.D., Daniels, J.A., \& D'Andrea, M.J., (2003). Community Counseling, Empowerment strategies for a Diverse Society, (3rd Ed.).

23. Melchert, T. P., Hays, V. L., Wiljanen, L. M., \& Kolocek, A. K. (1996). Testing models of counselor development with a measure of counseling self-efficacy. Journal of Counseling and Development, 74 (July/August), 640-644.

24. Miller, G. M. \& Neese, L. A. (1997). Self-esteem and reaching out: Implications for service learning. Professional School Counseling, 1(2) (Dec 1997), 29-32. 
25. Munger, R. L. (1997). Ecological trajectories in child mental health. In S. W. Henggeler \& A. B. Santos (Eds.), Innovative approaches for difficult-to-treat populations (pp. 3-26). Washington, D.C.: American Psychiatric Press.

26. Osborne, J. L., Collison, B. B., House, R. M., Gray, L. A., Firth, J., \& Lou, M. (1998). Developing a social advocacy model for counselor education. Counselor Education and Supervision, 37(March), 190-202.

27. Seymour, C. \& Vaccaro, P. (2001). Service changes lives. Conversations, Fall (20), 18-22.

28. Spohn, W. C. (2001). The university that does justice. Conversations, 19 (Spring), 4-12.

29. Stafford-Levy, M. \& Wiburg, K. M. (2000). Multicultural Technology Integration: The Winds of Change Amid the Sands of Time. Computers in the schools, 16 (3/4), 121-134.

30. Super, D. (1990). A life-span, life-space approach to career development. In D. Brown, L. Brooks, \& Associates (Eds.), Career Choice and Development ( $2^{\text {nd }}$ Ed.). San Francisco: Jossey-Bass.

31. Swezey, E. D. (1990). Grounded in justice: Service learning from a faith perspective. New Directions for Student Services, 50(Sum 1990), 77-90.

32. Van Voorhis, P., Braswell, M., \& Morrow, B. (1997). Family therapy. In P. Van Voorhis \& M. Braswell \& D. Lester (Eds.), Correctional counseling and rehabilitation (3rd Ed.). Cincinnati, OH: Anderson Publishing Co.

33. Ward, K. \& Wolf-Wendel, L. (2000). Community-centered service learning: Moving from doing for to doing with. American Behavioral Scientist, 43 (5), 767-780.

\section{APPENDIX 1}

\section{Knowledge and Competence Pre-Questionnaire}

On History and Systems of Community and Agency Counseling

Developed by Dr. Margery Shupe \& Dr. Bill O’Connell

Xavier University, Cincinnati, Ohio

Read each statement and rate your level of agreement or disagreement using the following scale:

\begin{tabular}{llllcc}
1 & 2 & 3 & 5 & 6 & 7 \\
Strongly Agree & & & & & Strongly Disagree \\
\hline
\end{tabular}

Rate your of knowledge in the following areas:

1. Training and preparation standards, credentialing, licensure standards to become a professional counselor.

2. Familiarity with multiple functions and roles that counselors may fill in an Agency setting.

3. Best practice principles for common diagnostic presentations in Agency settings.

4. The meaning of advocacy in community-based settings.

5. The benefits and limitations of family counseling in community based mental health settings.

6. Eligibility standards, admission procedures, intake and orientation in a community-based counseling agency.

7. Dual diagnosis and implications for treatment planning.

8. Impact of Medicaid and Medicare policies on counselor activity 
9. Three types of intervention in community based settings.

10. The relationship between major historical developments and counselor identity.

11. The benefits and limitations of research to program development and evaluation.

12 The benefits and limitations of multidisciplinary intervention strategies in Agency settings.

13. American Counseling Association (ACA) and your state board code of professional ethics and rules.

14. Professional organizations, such as ACA, its divisions, branches, and affiliates, including membership benefits, activities, services to members, and current mission and philosophy.

15. Multicultural and pluralistic trends, including characteristics and concerns between and within diverse groups nationally and internationally.

16. Ability to articulate a philosophy of counseling to guide helping behaviors.

17. Ability to manage time between face-to-face helping, documentation, collateral contact and discharge planning.

18. Using computer based software to complete traditional client documentation.

19. Identify the counseling needs of minority groups, including African American persons, women, poor, illiterate, disabled and homosexual persons.

20. Ability to evaluate program effectiveness for a particular population.

21. The role of the supervisee in maintaining a clinical supervision relationship.

22. Articulate the purpose of an organizational mission.

23. Use of technology for education and research.

24. Articulating my future role as a professional counselor, my functions, and relationships with other human service providers.

25. Counselor advocacy processes needed to address institutional and social barriers that impede access, equity, and success for clients.

26 Promoting clients understanding and access to community resources.

27. Effective strategies for locating and referring a client to be seen by the appropriate community agency or service.

28. Conflict resolution principles and techniques.

29. Applying multicultural counseling approaches through cultural self-awareness, and recognition of the nature of biases, prejudices, and processes of intentional and unintentional oppression and discrimination, and other culturally supported behaviors that are detrimental to the growth of the human spirit, mind or body.

30. Using service learning to enhance my understanding and role as a future counselor. 